\section{The relationship between emotional regulation difficul- ties and subjective well-being in children aged 6-7 years}

\author{
Anik indarwati, Martini Jamaris, \\ Elindra Yetti
}

Early Childhood Education, Universitas Negeri Jakarta, Indonesia

\begin{abstract}
A number of studies have shown the relationship between emotional regulation difficulties and subjective well-being. Reappraisal is considered a form of emotional regulation better than suppression. However, suppressing emotional expression increases the activity of physiological responses which actually harms the human health in the long run. Early age children still have difficulty in regulating their emotions, and this is likely to affect their psychological well-being if not properly managed. This study aims to examine the relationship between emotional regulation difficulties and subjective wellbeing in children aged 6-7 years. Study participants $(\mathrm{N}=55)$ were children in their early childhood who were transitioned from kindergartens to Gorontalo elementary school. Data were obtained through questionnaires using an Emotional Regulation Checklist / ERC (shiedls \& ciccheti, 2003) and subjective welfare questionnaire. Based on data analysis using Pearson product moment correlation test, the researcher found that the correlation coefficient (rxy) is 0.408 with $\mathrm{p}=0.000$ (p $<0.01)$. This indicates that there is a significant negative relationship between the variable of the value of emotional regulation difficulties with subjective wellbeing.
\end{abstract}

\section{Introduction}

Subjective well-being illustrates the degree of happiness function in children. Diener defines it as a phenomenon of the type of individual with positive and negative values which includes cognitive and affective evaluation which is explained in three aspects, namely life satisfaction, positive and negative effects. ${ }^{1}$ Thompson said that these three aspects are not only in adults but in children and adolescents. Wellbeing describes the quality of life of children, which is a major concern used to identify their problems, knowing what happened, why it happened, and giving preventive attention to the quality of children. $^{2}$

The term children well-being in Indonesia's laws and regulations is stated in Act No. 4 of 1979 . It is stated in clause 1 that child well-being is a system of life and livelihood of children ensure the growth and development of children in a natural manner, both spiritually, physically and socially. The concept needs to be operationalized in the context of children thereby, monitoring their level of wellbeing. The results of the 2018 population census projection in Indonesia is estimated at 252.2 million people, and around 82.85 million (32.9 percent) of them are children aged $0-17$ years. Therefore, investing in children is similar to analyzing a third of Indonesia's population. The current picture of a child's condition is an important basis for taking appropriate policies for children. ${ }^{3}$

Government efforts carried out so far have not been fully able to improve the well-being and protection of children. In the field of education (sussenas, 2003), school enrollment rates (APS) of children aged 712 years, $13-15$ years and 16-18 years are $96.4 \%, 81.0 \%$, and $51.0 \%$ respectively. In the same year, children aged 3-4 and 5-6 years and who attended preschool education were only about 12.78 and 32.9 percent respectively. In the field of health, infant mortality rates, the lack of nutrient in children under five years, and the prevalence of IDD/GAKY (disruption due to iodine deficiency) in elementary school children is still high. ${ }^{4}$

Subjective well-being is broadly divided into two perspectives, namely hedonic who believe that happiness is related to positive emotions and eudaemonics those who believe that happiness is related to the struggle for success. According to the hedonic view, happiness contains a person's ability to balance positive and negative feelings, thereby staying satisfied. This subjective well-being by Keyes is known as emotional well-being which comprises of 6 components, namely cheerfulness, enthusiasm, happiness, calmness, satisfaction and full of life..$^{5}$ While the eudaimonic view is related to subjective well-being, and also consists of 6 components, namely self-acceptance, positive relationships with others, independence of the ability to face environmental stress, having a purpose in life and personal growth. ${ }^{6}$

Interviews with parents show that behavior complained by children is mostly related to emotions. In general, children display hurtful behavior when feeling angry
Correspondence: Anik indarwati, Doctoral Program of Early Childhood Education, Faculty of Early Childhood Education, Universitas Negeri Jakarta, Gedung Daksinapati, Rawamangun Muka, Jakarta Timur 13220, Indonesia.

Tel./Fax: +62.21 .4755115$

E-mail: anikindarwati_paud16s3@mahasiswa.unj.ac.id

Key words: subjective well-being, emotional regulation difficulties, children aged 6-7 years.

Acknowledgment: the authors would like to thank the Doctoral Program of Early Childhood Education, Faculty of Early Childhood Education, Universitas Negeri Jakarta, Indonesia.

Contributions: the authors contributed equally

Conflict of interest: the authors declare no potential conflict of interest.

Funding: none.

Clinical trials: the study is not involved any clinical trials.

Conference presentation: part of this paper was presented at the $3 \mathrm{rd}$ International Symposium of Public Health, 2018 October 31 - November 1, Universitas Airlangga, Surabaya, Indonesia

Dedication: the article is dedicated to Doctoral Program of Early Childhood Education, Faculty of Early Childhood Education, Universitas Negeri Jakarta, Indonesia.

Received for publication: 28 July 2019.

Revision received: 9 September 2019

Accepted for publication: 15 October 2019.

This work is licensed under a Creative Commons Attribution NonCommercial 4.0 License (CC BY-NC 4.0).

CCopyright: the Author(s), 2019

Licensee PAGEPress, Italy

Journal of Public Health in Africa 2019; 10(s1):1210 doi:10.4081/jphia.2019.1210

by hitting, damaging objects, shouting, mocking and fighting with friends. The behavioral forms listed are seen in the form of abusive behavior, hurting and withdrawing. These behavioral problems are related to the emotions of the child and is in line with the results of a research carried out by Havinghurst. ${ }^{7}$ According to him, children who have behavioral problems lack understanding of emotions and its regulation. Emotional regulation plays the role of a key when interacting with 
the environment. ${ }^{8}$ It is an action conducted by someone to control the emotions they want to experience, how and when these emotions are raised, how to express it or how it is seen by others. ${ }^{9}$ In children, emotion regulation is described as the ability to recognize the emotions of oneself and others and the ability to communicate their feelings. ${ }^{10}$ It is also the ability to control and interact with others according to social rules. ${ }^{11}$

The process of child development which is slow in regulating their behavior becomes an issue on the emotional social aspects of children during elementary school. ${ }^{12}$ Denham states that children who are not easily angry and look happy are preferred by their playmates, considered friendly and easily invited to work with by teachers. ${ }^{7}$ While those who are better at regulating emotions show lower aggression when interacting with peers, fewer behavioral problems in preschool and elementary school. Problematic behavior continues when the child reaches adolescence and adulthood, when compared to children who have good emotional regulation ability, for example the emergence of problems of aggression or depression. Correspondingly, longitudinal research shows that the inability to regulate emotions is an important risk factor in the formation of aggressive behavior. ${ }^{13}$ The is called emotional dysregulation. Some examples of behavioral profiles of emotional dysregulation that arise in school children include shouting, unable to wait, demands that must be met, hurting, damaging own property, other people's property, beating, unable to sit quietly, and running continuously. ${ }^{13}$ These behaviors are of course not in accordance with social norms and have the potential to harm themselves and others.

The results of the study succeeded in revealing well-being indicators that emerged in aspects of social, health, and academic relations. In social relations, the prosperous ones are more confident, is willing to share, has good conflict resolution, is able to empathize, has a creative way of thinking that makes it easy to establish social relations, and likes himself and others. Prosperous people are more empathetic, show more social attitude towards others, easily establish social relations, are altruistic, willing to share, active, confident, like themselves and others, have good and creative conflict resolution. ${ }^{14}$ Prosperity also makes a person possess better psychosocial functions.

Research in the fields of physical and mental health shows that people who feel prosperous show high immunity therefore, they are rarely infected by diseases. ${ }^{16}$ They also displayed low levels of depression, negative affect, and social stress. ${ }^{15}$ Conversely, people with low well-being tend to assume that the events they experience are unpleasant therefore, they negatively become easily ignited, depressed, anxious, aggressive, or feel dissatisfied with their physical form. Based on the above problems this study aims to look at the relationship of emotional dysregulation behavior with subjective well-being in children aged 6-7 years.

\section{Materials and Methods}

This is a quantitative research with correlational design in which the researchers measured two classified variables, namely independent and dependent. The independent variable comprises of emotional regulation difficulties while the independent variable is subjective wellbeing.

The population in this study were elementary school children studying in Gorontalo. The number of subjects used are 55 people, while the purposive sampling was used to determine the characteristics, of early childhood in children aged 6-7 years, from schools in Gorontalo district. The data collection method used is in the form of psychological scales which measures children's emotional regulation adapted from the instrument Emotion Regulation checklist (ERG) from Shields and Ciccheti.18 The ERG instrument consists of 16 items emotional dysregulation subscale and 8 items of emotion regulation subscale culminating in 24 items. Subjective wellbeing in the form of SWB-SWLS scale consists of positive affect sub-scale, negative Affect sub-scale, and global life satisfaction subscale, while SWB-PLS measures subjective well-being in personal life. Analysis techniques used Spearman correlation by utilizing statistical packages for social science (SPSS) version 22.0.

Table 1. Scale categories of emotional regulation difficulties and subject's score distribution.

\begin{tabular}{lcc} 
Category & Subject & Presentation \\
Low & 0 & 0 \\
Medium & 12 & $21.8 \%$ \\
\hline High & 43 & $78.2 \%$ \\
Total & 55 & $100 \%$ \\
\hline
\end{tabular}

\section{Results}

The results showed categories of emotional regulation difficulties, categories of subject wellbeing and subject's score distribution.

Table 1 noted from subject's score categories that those who had regulation difficulties and emotional regulation score of low category were 0 . While 12 subjects had medium score regulation difficulties, 43 subjects had high score emotional regulation.

From Table 2, the high score of subjective wellbeing was 0 , while score for medium category was 13 and low category scored 42 .

\section{Discussion}

Based on data analysis using Pearson product moment correlation test, the researcher found that the correlation coefficient (rxy) is 0.408 with $\mathrm{p}=0.000$ $(p<0.01)$. This indicates that there is a significant negative relationship between the variable of the value of emotional regulation difficulties with subjective wellbeing, because $r=-0.408$ and significance value of $0.005 \quad(\alpha<0.01)$. Negative correlation and high significance indicate that the research hypothesis is accepted. The results of this research indicates that children who have high emotional regulation difficulties also possess low subjective wellbeing, while those with low emotional regulation difficulties have high subjective wellbeing.

Keyes examined 1200 children aged 612 years to uncover children's well-being from a mental health perspective. This is divided into three types, namely emotional, psychological, and social well-being. The results show that emotional well-being in children occupies the strongest position, followed by social and psychological wellbeing. ${ }^{16}$ Children who show certain behavior such as aggression, anger, depression or anxiety are indications of low well-being in children. This happens as children

Table 2. Scale categories of subject wellbeing and subject's score distribution.

\begin{tabular}{lcc} 
Category & Subject & Presentation \\
Low & 42 & $72.4 \%$ \\
Medium & 13 & $23.6 \%$ \\
\hline High & 0 & 0 \\
Total & 55 & $100 \%$
\end{tabular}


experience both physiological and psychological changes. They face changes to cope with their emotional life due to unpreparedness. Increasing subjective wellbeing will reduce the intensity of aggression, depression or anxiety. ${ }^{17}$

Erikson emphasized the age of 6-12 years as the emergence sense of accomplishment where children feel ready to accept demands which arises from others and carry out or resolve the claim. This condition makes children of this age able to learn to control their emotions and behavior if the child feels less like the task given to him.

Children aged 6-7 years already know the emotions they feel and show or hold emotional expressions in accordance with what their social environment expects. This shows the child's ability to regulate emotions, even though it is simple. Children who show behavioral problems tend to experience difficulties in regulating emotions. This is caused by lack of individuals in displaying skills in expressing emotions that are felt right. ${ }^{7}$ Given this deficiency, children with behavioral problems find it difficult to regulate or hold negative emotions which often appear with higher intensity or long duration. Children who experience this condition are said to be emotionally dysregulated.

Emotions plays an important role in shaping children's subjective well-being. Diener explains well being as a multidimensional construct which positively impacts on attitudes such as joyous emotions. ${ }^{17}$ Negative well-being also affects emotions such as experiencing anxiety. The point is that someone with high well-being is an individual with positive emotional experience, and infrequently involved with emotions and a high level of life satisfaction.

Subjective well-being is considered a factor which reduces the existence of mental stress, and is an indicator of good life quality in individuals and the society. ${ }^{17}$ According to Veenhoven, happiness is part of subjective well-being that facilitates social interaction. When a child is in a happy condition, a positive effect leads to an active and energetic feeling, making it more productive. The happiness they experience reduces stress levels. Therefore understanding children's emotions help them to achieve their mental health.

Optimizing early childhood emotionalsocial development could be done by responding and understanding children's feelings, self-control training and managing emotions, applying discipline with the concept of empathy, training communication and social skills, creating a positive climate in the child's environment and exercising empathy and care for others. ${ }^{18}$

\section{Conclusions}

This study concludes that children who experience emotional dysregulation tend to have low subjective wellbeing. However, if they are trained early to be able to to understand emotions and the importance of controlling it positively, with a high sense of subjective wellbeing for a peaceful atmosphere or state of peace, thereby achieving happiness in life, and obeying rules in their social environment.

\section{References}

1. Diener E, Ryan K. Subjective WellBeing: A General Overview. South African Journal of Psychology 2009;39(4):391-406.

2. Thompson S, Aked J. A guide to measuring children's well-being. Practical Guide 2 2009. Available from: http://www.actionforchildren.org.uk/me dia/62864/a_guide_to_measuring_childrens_well-being.pdf. Accessed on: 3 January 2018.

3. Badan Pembinaan Hukum Nasional. Undang-Undang Republic Indonesia Nomor 4 Tahun 1979 Tentang Kesejahteraan Anak 1979. Available from: http:/www.bphn.go.id/data/documents/79uu004.pdf. Accessed on: 10 August 2018.

4. Faturochman F, Tyas TH, Minza WM, et al. Psikologi untuk kesejahteraan masyarakat. Yogjakarta: Fakultas Psikologi UGM; 2012.

5. Keyes CLM. The nature and importance of positive mental health in America's adolescents. In R. Gilman, E. S. Huebner, \& M. J. Furlong (Eds.), Handbook of positive psychology in schools (pp. 9-23). New York, NY, US: Routledge/Taylor \& Francis Group; 2009.

6. Ryff CD. Happiness Is Everything, or Is It? Explorations on the Meaning of Psychological Well-Being. Journal of Personality and Social Psychology
1989;57(6):1069-1081.

7. Denham SA, Caverly S, Schmidt M, et al. Preschool understanding of emotions: contributions to classroom anger and aggression. J Child Psychol Psychiatry 2002 Oct;43(7):901-16.

8. Callear A, Harvey ST, Bimler D. Understanding the structure of children'semotion-regulation strategies. International Journal of Behavioral Development 2016;41(3):456-462.

9. Gross JJ. Emotion regulation: Affective cognitive and social consequences. Psychophysiology 2002;39(3):281-91.

10. Papalia DE, Olds SW, Feldman R.D. Human development perkembangan manusia edisi 10 buku 2. Jakarta: Salemba Humanika; 2009.

11. Whitebread D, Basilio M. The emergence and early development of selfregulation in young children 2012;16(1):15-33.

12. Scanlon CL. Emotion regulation in children: a guide for teachers. Pennsylvania: University of Pittsburgh; 2010.

13. Achenbach TM, Edelbrock C, Howell CT. Empirically based assessment of the behavioral/emotional problems of 2and 3- year-old children. J Abnorm Child Psychol 1987;15(4):629-50.

14. Chase E, Statham J. Childhood Wellbeing: A Brief Overview. (Childhood Wellbeing Research Centre 1 , pp. pp. 1-18 ). London: Institute of Education, Loughborough University \& University of Kent; 2010.

15. Barkan SE, Greenwood SF. Religious Attendance and Subjective Well-Being among Older Americans: Evidence from the General Social Survey. Review of Religious Research 2003;45(2):116.

16. Cicchetti D, Ackerman B, Izard, C. Emotions and emotion regulation in developmental psychopathology. Development and Psychopathology 1995;7(1):1-10.

17. Diener E, Wirtz D, Tov W, et al. New Well-being Measures: Short Scales to Assess Flourishing and Positive and Negative Feelings. Social indicator research 2010;97:143-156.

18. Bretherton I. The Origins of Attachment Theory: John Bowlby and Mary Ainsworth. Developmental Psychology 1992; 28(5):759-775. 